\title{
Analysis of the influence of gravel size on the temperature field of crushed stone subgrade
}

\author{
Zhao Shi-chen 1,a, ${ }^{*}$, Mao Xue-song ${ }^{1, b}$, Zhang Bao-long ${ }^{2, c}$ \\ 1.School of highway, Chang'an University, Xi'an, 710064, China \\ 2.College of Geology Engineering and Geomatics, Chang'an University, Xi'an, 710064, China \\ aemail: 2275608611@qq.com \\ bemail: bxuesongxian@aliyun.com
}

Keyword: Gravel roadbed, Particle size, Temperature field, ABAQUS

\begin{abstract}
This document is based on the gravel test subgrade paved at the $\mathrm{K} 3012$ of the Qinghai-Tibet Highway near the Wudaoliang section, a large finite element software Abaqus is used to simulate the temperature field of gravel subgrade, and the influence of the particle size temperature field is obtained. The results show that both the $2-4 \mathrm{~cm}$ and the $10-15 \mathrm{~cm}$ gravel subgrade can protect the permafrost under the roadbed well, but the gravel subgrade with $6-8 \mathrm{~cm}$ diameter is lower than that, which is more favorable to the stability of permafrost.
\end{abstract}

\section{Introduction}

The gravel roadbed is one of the more effective roadbed forms, it can protect the frozen soil by setting a certain thickness gravel layer in the roadbed body to maintain the stability of the roadbed. Jiang fan[1], the two-dimensional "block-stone model" is established, and the Navier-stokes equation is used to describe the flow state of the air in the block gravel embankment; Xu Xue-zu [2] and so on the different particle size of the crushed stone in the cylindrical plexiglass tube, in the top temperature cycle fluctuations in the temperature of its internal changes in the law of the study, found in the top opening of the gravel layer in the presence of convective heat transfer mechanism; Wang Shuang-jie[3], the natural convection effect in the closed block gravel layer with the size of $6-8 \mathrm{~cm}$ is studied in laboratory, and it is found that under the condition of the peak temperature fluctuation, the natural convection cooling effect is favorable for the stability of the embankment in the cold region, and the more the thickness is, the more natural convection cooling effect is.

\section{ABAQUS Numerical Simulation}

\subsection{Geometrical Model Establishment}

In order to simulate the actual temperature condition of gravel roadbed, this paper establishes the height of the roadbed as $2.6 \mathrm{~m}$, the gravel diameter is $2-4 \mathrm{~cm}, 6-8 \mathrm{~cm}, 10-15 \mathrm{~cm}$, gravel thickness $1.2 \mathrm{~m}$, the gravel layer is at the bottom of the subgrade, $0.5 \mathrm{~m}$, the road width is $7 \mathrm{~m}$, the slope is $1: 1.5$, in order to simplify the calculation model, Save the computer time and occupy the space, regardless of the roadbed yin-yang slope effect, along the gravel roadbed symmetry axis takes the entire section $1 / 2$ to carry on the analysis. Finite element analysis model diagram of the temperature field of crushed stone subgrade as shown in Figure . 1. 


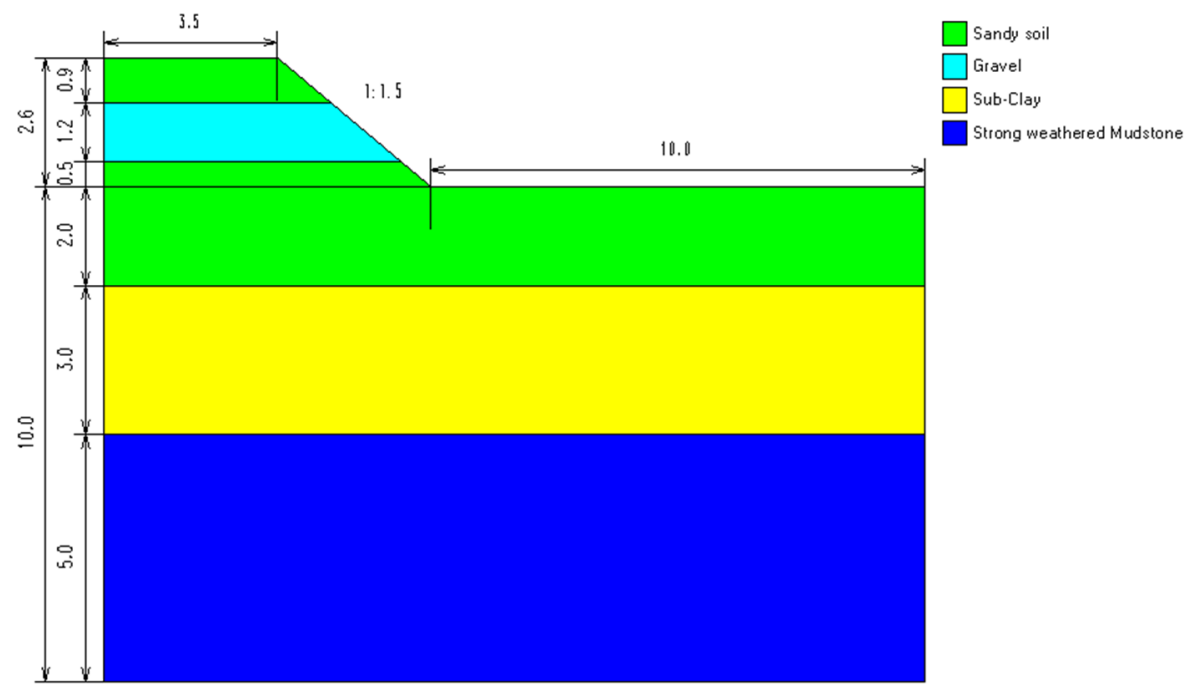

Fig. 1.Schematic diagram of finite element model

\subsection{Grid Division}

In the slope range, the Quadrilateral method is used to divide the model, that is, the triangular element is allowed in the transition region, the transition from coarse to fine is realized, and the quadrilateral element is used in the other range. In the gravel filled part of the mesh grid, so that the grid encryption.

\subsection{Thermal physical parameters of the material}

According to the geologic drilling data during the construction of the test project, the soil condition of the typical roadbed can be obtained, and the roadbed soil of the test project will be determined.

\subsubsection{Thermal physical parameters of soil}

The soil types and various thermal physical parameters are obtained by combining the existing measured data and relevant references, as shown in table. 1.

Table. 1. Thermal parameters and characteristic parameters of soil

\begin{tabular}{|c|c|c|c|c|c|c|c|c|c|}
\hline \multirow[t]{2}{*}{ Ordinal } & \multirow[t]{2}{*}{ Name } & \multirow{2}{*}{$\begin{array}{c}\text { Dry } \\
\text { density } \\
\mathrm{kg} / \mathrm{m}^{3}\end{array}$} & \multirow[t]{2}{*}{$\begin{array}{c}\text { Moisture } \\
\%\end{array}$} & \multirow[t]{2}{*}{$\begin{array}{l}\text { Density } \\
\mathrm{kg} / \mathrm{m}^{3}\end{array}$} & \multicolumn{2}{|c|}{$\begin{array}{l}\text { Coefficient of } \\
\text { thermal } \\
\text { conductivity } \\
\mathrm{W} /\left(m \cdot{ }^{\circ} \mathrm{C}\right)\end{array}$} & \multicolumn{2}{|c|}{$\begin{array}{l}\text { Specific heat } \\
\text { capacity } \\
\mathrm{J} /\left(\mathrm{kg} \cdot{ }^{\circ} \mathrm{C}\right)\end{array}$} & \multirow{2}{*}{$\begin{array}{c}\text { Phase } \\
\text { Change } \\
\text { Heat } \\
\mathrm{J} / \mathrm{kg}\end{array}$} \\
\hline & & & & & $f$ & $\mathrm{u}$ & $\mathrm{f}$ & $\mathrm{u}$ & \\
\hline $\mathrm{I}$ & grit & 1700 & 10 & 1870 & 2.2 & 1.68 & 856.52 & 1102.51 & 15766.4 \\
\hline III & Sub-Clay & 1500 & 35 & 2025 & 2.12 & 1.36 & 1255.65 & 1703.8 & 39229.3 \\
\hline IV & $\begin{array}{c}\text { Strong } \\
\text { weathered } \\
\text { Rock }\end{array}$ & 2404 & 4 & 2500 & & & & & 0 \\
\hline
\end{tabular}

Note: f-Frozen state; u-No frozen state

\subsubsection{Thermal physical parameters of Gravel}

The thermal physical parameters of the gravel used during the calculation are shown in table. 2 . 
Table. 2. Thermal physical parameters of Gravel

\begin{tabular}{|c|c|c|c|c|c|c|c|c|c|c|}
\hline \multirow[t]{2}{*}{ Ordinal } & \multirow{2}{*}{\multicolumn{2}{|c|}{ Name }} & \multirow[t]{2}{*}{$\begin{array}{c}\text { Dry } \\
\text { density } \\
\mathrm{kg} / \mathrm{m}^{3}\end{array}$} & \multirow[t]{2}{*}{$\begin{array}{c}\text { Moisture } \\
\%\end{array}$} & \multirow[t]{2}{*}{$\begin{array}{l}\text { Density } \\
\mathrm{kg} / \mathrm{m}^{3}\end{array}$} & \multicolumn{2}{|c|}{$\begin{array}{l}\text { Coefficient of } \\
\text { thermal } \\
\text { conductivity } \\
\mathrm{W} /\left(m \cdot{ }^{\circ} \mathrm{C}\right)\end{array}$} & \multicolumn{2}{|c|}{$\begin{array}{c}\text { Specific } \\
\text { heat } \\
\text { capacity } \\
\mathrm{J} /\left(\mathrm{kg} \cdot{ }^{\circ} \mathrm{C}\right)\end{array}$} & \multirow[t]{2}{*}{$\begin{array}{l}\text { Phase } \\
\text { Change } \\
\text { Heat } \\
\mathrm{J} / \mathrm{kg}\end{array}$} \\
\hline & & & & & & $\mathrm{f}$ & $\mathrm{u}$ & $\mathrm{f}$ & $\mathrm{u}$ & \\
\hline \multirow{3}{*}{ II } & \multirow{3}{*}{$\begin{array}{l}\text { Gravel } \\
\text { Layer }\end{array}$} & $2-4 \mathrm{~cm}$ & 2000 & 0 & 2000 & 1.038 & 0.346 & 825 & 904 & 0 \\
\hline & & $6-8 \mathrm{~cm}$ & 2000 & 0 & 2000 & 1.188 & 0.396 & 769 & 839 & 0 \\
\hline & & $10-15 \mathrm{~cm}$ & 2000 & 0 & 2000 & 1.326 & 0.442 & 714 & 774 & 0 \\
\hline
\end{tabular}

\subsection{Boundary conditions}

The purpose of this paper is to analyze the influence of gravel design parameters on the cooling effect of gravel subgrade, so the influence of boundary condition is simplified in the analysis of this paper, and the first kind of boundary condition is considered synthetically according to the "Boundary layer principle". The upper boundary condition of the model adopts the Weather Service data center to provide the measured ground temperature of the earth below $50 \mathrm{~cm}$, the geothermal temperature of the Qinghai-Tibet Plateau basically satisfies the variation rule of the sine function, considering the influence of the climate warming, assuming the geothermal temperature satisfies the standard sine function, its form is:

$$
\mathrm{T}=\mathrm{a}_{0}+\mathrm{b}_{0} \mathrm{t}+\mathrm{b}_{1} \sin \left(\mathrm{b}_{2} \mathrm{t}+\mathrm{c}_{0}\right)
$$

In the formula: $\mathrm{T}$ is the temperature; $\mathrm{t}$ is the time in seconds; $\mathrm{a}_{0}, \mathrm{~b}_{0}, \mathrm{~b}_{1}, \mathrm{~b}_{2}, \mathrm{c}_{0}$ is pending parameter.

According to the measured ground temperature observation data, using the least square method, we can find the corresponding parameters in the typical section.

The detailed temperature changes are shown below:

The temperature variation law of pavement at the top of roadbed is:

$$
\mathrm{T}=1.29+1.27 \times 10^{-9} \mathrm{t}+18.22 \sin \left(1.99 \times 10^{-7} \mathrm{t}-1.83\right)
$$

The temperature variation law of subgrade slope is:

$$
\mathrm{T}=-2.13+1.27 \times 10^{-9} \mathrm{t}+9.5 \sin \left(1.99 \times 10^{-7} \mathrm{t}-2.09\right)
$$

The law of temperature variation of natural surface is:

$$
\mathrm{T}=-4+1.27 \times 10^{-9} \mathrm{t}+8.55 \sin \left(1.99 \times 10^{-7} \mathrm{t}-2.09\right)
$$

Because of the limited influence of subgrade on permafrost in adjacent area, the right boundary of the model is defined as adiabatic boundary, and because the model is part of the symmetric model, the symmetric axis (left boundary of model) is also defined as adiabatic boundary. The bottom boundary conditions at $10 \mathrm{~m}$ below the natural ground of the roadbed are taken $2{ }^{\circ} \mathrm{C}$. The initial calculation time is October 5, 2017, the initial condition roadbed filling temperature is $3{ }^{\circ} \mathrm{C}$.

\section{Simulation Results Analysis}

In order to analyze the influence of particle size, the vertical temperature variation of median and right shoulder of roadbed in use for 11 years in three kinds of cases were analyzed, and the specific changes were described as follows.

1. Temperature vertical variation of October 5,10 th year

Fig. 2 and Fig. 3 are the curves of the temperature varying with the depth of center line and right shoulder of roadbed in October 5, 10th year. 


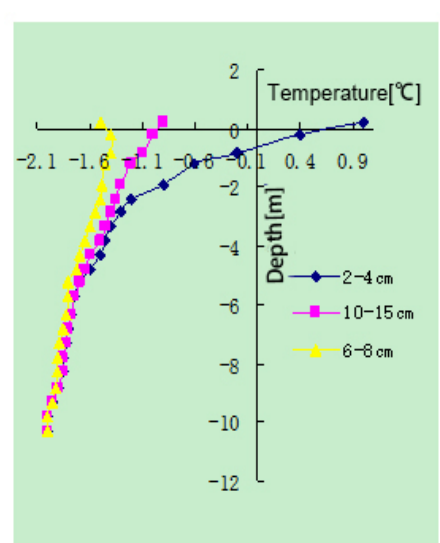

Fig. 2 Variation of temperature with depth in the middle road.

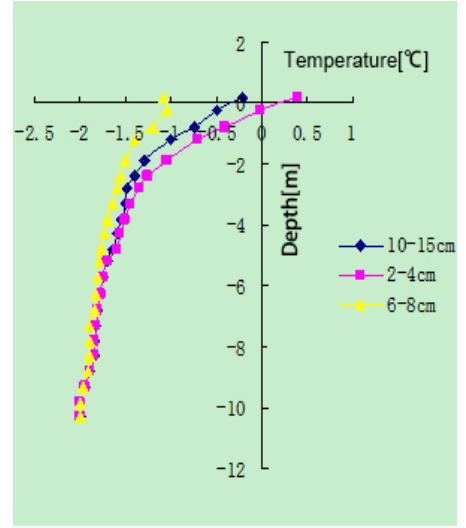

Fig. 3 Variation of temperature with depth in the right shoulder of road.

As shown in Figure 2 and figure 3, for this section of the gravel roadbed form, the roadbed of $2-4 \mathrm{~cm}$ is melted, its depth is approximately on the natural ground, the roadbed of other grain diameter does not appear to melt. since the position of $0.5 \mathrm{~m}$ from the surface to the ground near $2 \mathrm{~m}$, the temperature of the gravel roadbed is rapidly reduced, then with the further increase of the depth, the difference between different grain sizes Gradually shrinking, and tending to- $2{ }^{\circ} \mathrm{C}$. At the same depth, the temperature of subgrade with different grain size is different, the temperature of gravel subgrade with $2-4 \mathrm{~cm}$ grain diameter is higher than that of $10-15 \mathrm{~cm}$, and $10-15 \mathrm{~cm}$ is higher than $6-8 \mathrm{~cm}$.

2. Temperature vertical variation of February 5,11 th year

Take 11 years after the lowest temperature month that is February to draw the vertical temperature change chart of the roadbed center line and the shoulder. As shown in Figures 4 and 5.

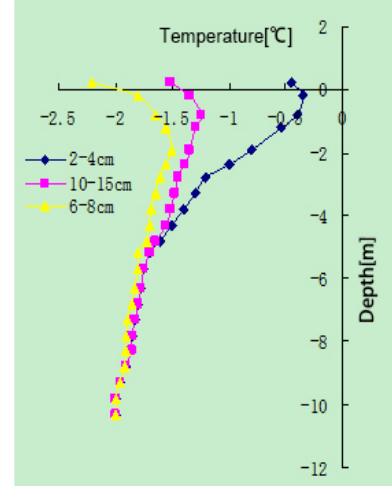

Fig. 4 Variation of temperature with depth in the middle road.

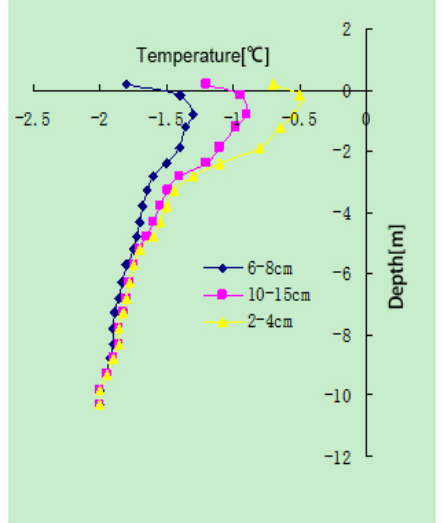

Fig. 5 Variation of temperature with depth in the right shoulder of road.

As shown in Fig. 4 and Fig. 5, all subgrade forms are negative temperature, the roadbed of $2-4 \mathrm{~cm}$ grain size did not appear similar to the melting phenomenon of October, which showed that the gravel subgrade with small diameter can also better introduce the outside cold quantity at this time, thus reducing the soil temperature. With the increase of depth, the temperature of the gravel subgrade is slightly uplifted, and a peak is present near the ground. Value, and then gradually descend, and tend to $-2{ }^{\circ} \mathrm{C}$, the corresponding difference between the different roadbed is gradually reduced; at the same depth, the temperature of subgrade with different diameters is different, the temperature of gravel subgrade with $2-4 \mathrm{~cm}$ grain diameter is higher than that of $10-15 \mathrm{~cm}$, and $10-15 \mathrm{~cm}$ is higher than $6-8 \mathrm{~cm}$.

3. Temperature vertical variation of August 5, 11th year

Take 11 years after the highest temperature month that is August to draw the vertical temperature change chart of the roadbed center line and the shoulder. As shown in Figures 6 and 7. 


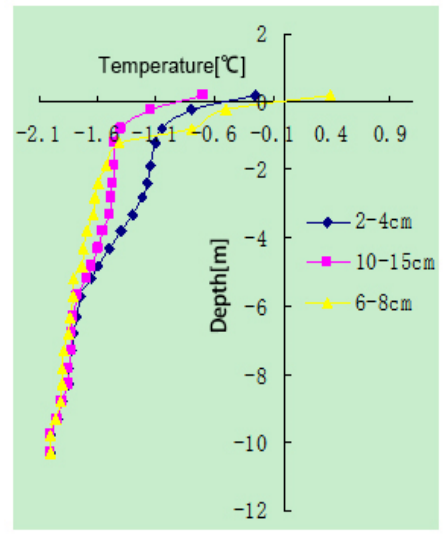

Fig. 6 Variation of temperature with depth in the middle road.

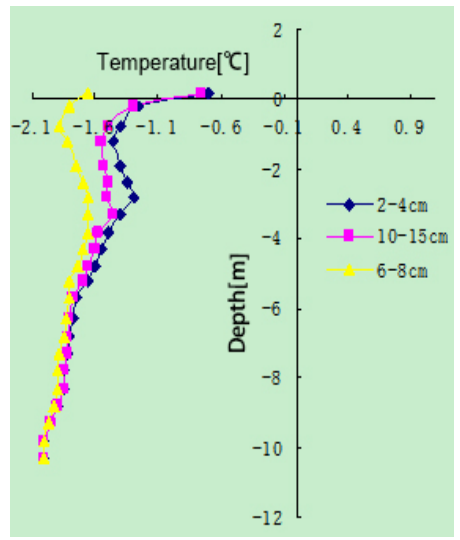

Fig. 7 Variation of temperature with depth in the right shoulder of road.

From figures 6 and 7, you can see that the same period, whether it is the mid line of the roadbed or the shoulder, basically, the $2-4 \mathrm{~cm}$ of gravel subgrade is higher than the $10-15 \mathrm{~cm}$, and the $10-15 \mathrm{~cm}$ is higher than the $6-8 \mathrm{~cm}$. The mid line temperature of the roadbed is higher at the $0.5 \mathrm{~m}-1 \mathrm{~m}$ depth from the ground to the $6-8 \mathrm{~cm}$ diameter gravel, even the part is higher than the $2-4 \mathrm{~cm}$ particle diameter, and the ground above the roadbed has reached the positive temperature. Except for the gravel subgrade above the ground $6-8 \mathrm{~cm}$, all the subgrade temperature is negative temperature, and the temperature is gradually decreasing and approaching, until the same.

\section{Conclusion}

(1) Overall, the same period, whether the mid line or the right shoulder, is basically $2-4 \mathrm{~cm}$ particle size of the gravel subgrade temperature is higher than the $10-15 \mathrm{~cm}$, and $10-15 \mathrm{~cm}$ is also higher than the $6-8 \mathrm{~cm}$;

(2) Three kinds of gravel subgrade in the year of three different dates, basically are in negative temperature, only $2-4 \mathrm{~cm}$ and $6-8 \mathrm{~cm}$ diameter of the roadbed on the individual date there are near the ground part of the foundation more than $0{ }^{\circ} \mathrm{C}$, this shows that the gravel roadbed has a good role in protecting the frozen soil;

(3) Visible from the above figures, the gravel roadbed with $10-15 \mathrm{~cm}$ grain diameter is all in negative temperature, and the $2-4 \mathrm{~cm}$ particle diameter is always higher than other grain diameter, and some dates have a deep roadbed whose temperature is close to $0{ }^{\circ} \mathrm{C}$ or even exceeding the $0^{\circ} \mathrm{C}$;6-8cm grain diameter, the gravel roadbed temperature is lower than other diameter in most cases, Only part of the date subgrade temperature is over $0{ }^{\circ} \mathrm{C}$, other times the temperature is lower;

\section{Acknowledgement}

This work was supported by the Special Found for Basic Scientific Research of Central College of Chang'an University (Grant NO.300102218408) and China Railway First Research Project 2016A-061. The authors gratefully acknowledged their financial support.

\section{References}

[1] Jiang Fan, Liu Shi, Wang Hai-gang, et al. Numerical calculation and analysis of heat transfer and convective characteristics of crushed (block) stone embankment in frozen soil [J]. China Science (Series D), 2003,33 (add): 133-144.

[2] Xu Xue-zu, Sun Bin-xing, Liu Qi, et al. Indoor test of the effect of gravel laying position and particle size on the cooling effect of subgrade [J]. Journal of Geotechnical Engineering, 2005,27 (3).

[3] Wang Shuang-jie, Sun Bin-xing, Xu Xue-zu, et al. Experimental study on the mechanism of natural convection of Embankment rock [J]. Journal of Chinese Highways, 2004,17 (2): 18-23. 